\title{
C-Thinking via E-learning: A Conceptual Paper about the Use of Digital Learning Tools for Reflective Thinking
}

\author{
Ayse Kok \\ University of Oxford, UK
}

\begin{abstract}
Learning in a world where traditional assessment of intelligence are radically changing and abundant knowledge is more readily available because of the proliferation of information communication technologies (ICTs) has become a challenge. Without focusing on how the technologies may provide the learners with critical thinking and analytical skills rather than the mere delivery of information may result in the mirroring of traditional didactic approaches on the technology. Especially, within the realm of social sciences where there is a gamut of information resources, developing discipline based critical and analytical thinking skills is essential to cope with the information overload. The goal of this paper is to provide a clear link between the use of new technologies in social sciences and the development of critical thinking skills.
\end{abstract}

\section{Introduction}

Critical thinking can basically be considered as being able to distinguish the true from the false. Despite being central to both intellectual and social progress, critical thinking is in short supply [19].

Bogdan [1] defines critical thinking as "a unique kind of purposeful thinking in which the thinker systematically and habitually imposes criteria and standards upon the thinking....”.

According to Dewey [4], reflective thought should be 'active, persistent', and should entail 'careful consideration of any belief or supposed form of knowledge in the light of the grounds that support it and the further conclusion to which it tends.' Similarly, critical thinking should include the evaluation of the worth, accuracy, or authenticity of various propositions, leading to a supportable decision or direction for action. As it has been stated in the 1980 California State University Executive Order which announced for the first time the requirement of formal instruction in critical thinking [5], critical thinking emphasizes mental attitudes of "analyzing, criticizing and advocating ideas and reasoning inductively and deductively and reaching factual or judgemental conclusions based on sound inferences drawn from unambiguous statements of knowledge”. Similarly, Paul, Elder, Bartell [15]; Perry [16] and Lampert [11] define critical thinking as recognizing differing viewpoints, being analytically reflective and willing to increase sources of information as well as generating meaningful questions to formulate plausible conclusions [4]. These traditional definitions of critical thinking are based on an internalist point of view that packs everything relevant to the evaluation of an intellectual product into the consciousness of an individual [3]. Accordingly, critical thinkers maintain conscious and deliberate access to the reasons for their beliefs and actions. On the other hand, the externalist point of view favors strategies related to intuitive and recognitional processes which may be more reliable for achieving goal in familiar situations or when time is limited [3]. This view focuses on the reliability of different types of processes for generating beliefs under different circumstances.

Freire [7] asserts that critical thinking can occur through the reciprocal process of connection, questioning and interaction among teachers and learners rather than depositing knowledge in the heads of students. So, a critical thinker should be able to differentiate between fact and opinion, examine the assumptions, be flexible and openminded be aware of fallacious arguments and stay focused on the big picture. According to Meyers [12], critical thinking is a learnable skill and students can collaborate to enhance their thinking. Meyers [12] also asserts that while courses should be assignment centered rather than text oriented goals should emphasize the use of content rather than simply its acquisition.

\section{Critical Thinking within the Realm of Social Sciences}

According to Meyers [12], instead of teaching critical thinking as an independent subject where the students are taught to master formal paradigms of reasoning, critical thinking should be incorporated wholly into the study of individual disciplines. Treating the courses in formal reasoning as being indispensable for a study of the arts and sciences similar to a medieval curricular practice may not provide by themselves the 
students with the wide range of specific critical skills appropriate to the study of the social sciences [12]. Rather, in order to teach critical thinking skills, "discipline-related frameworks for critical thinking" which can define as the distinctive conceptual structures and methodological norms that guide inquiry and shape theory in a given discipline should be transmitted [12]. As there is no unified critical methodology or a single procedure for teaching critical thinking skills in social sciences Meyers [12] suggests that based on the related intellectual culture and context a "step-wise approach" to the development of analytical skills an be followed. To exemplify, a series of short, carefully targeted and complex writing assignments may be given throughout the semester.

\subsection{Utilizing E-Learning}

Idea generation can be fostered through the bulletin boards in online learning environments by coaching the discussions to take the students' ideas to the next level and more intellectual learning whereas the presentation tools can be used for group projects. This kind of collaborative learning in pairs or groups with shared goals may promote critical thinking of the social science students. Yet, as not all of the students may possess critical thinking skills to advance an online discussion or all the faculty members may have the required expertise in monitoring the online discussions and creating productive communities of online learning support and training may be required. As Sugar and Bonk [18] stated peer collaboration and interaction may not necessarily trigger reflection on one's ideas. Reflective and substantive exchanges between social science students can occur if the faculty members can stimulate the discussions by asking probing questions, encouraging participation, holding them responsible for their thinking and coaching the students about collaborative learning. As asynchronous conversations allow for greater reflection via giving feedback students should also be made aware of the significance of their answers and learn to respect each others' ideas and construct their own understanding. Samples of similar technologies that may influence the depth of thinking of the students are shown in Table 1[8].

Table 1. Principle Based Strategies for Teaching

\begin{tabular}{|l|l|}
\hline Principles of Teaching & Examples of Technologies \\
\hline $\begin{array}{l}\text { Active and purposeful } \\
\text { engagement with abstracted } \\
\text { phenomena }\end{array}$ & $\begin{array}{l}\text { Simulations, microworlds, } \\
\text { virtual worlds }\end{array}$ \\
\hline $\begin{array}{l}\text { Multiplicity of perspectives } \\
\text { to be fully apprehended }\end{array}$ & $\begin{array}{l}\text { Multidisciplinary online } \\
\text { resources such as wikis, blogs, } \\
\text { open educational resources, } \\
\text { podcasts }\end{array}$ \\
\hline
\end{tabular}

\begin{tabular}{|l|l|}
\hline $\begin{array}{l}\text { Relatedness for } \\
\text { meaningful understanding }\end{array}$ & $\begin{array}{l}\text { Chatrooms, forums, podcasts, } \\
\text { online discussions about case } \\
\text { studies, concept maps }\end{array}$ \\
\hline $\begin{array}{l}\text { Diversity of } \\
\text { instructional methods }\end{array}$ & $\begin{array}{l}\text { Inquiry based online discussion } \\
\text { forums, wikis that encorage } \\
\text { collaborative online writing } \\
\text { activities }\end{array}$ \\
\hline
\end{tabular}

Furthermore, small group discussions about a particular reading, case discussions using simulated complex problems for analysis, debating teams or mock trials where students assume various roles may be utilized. To exemplify, as van Gelder [19] suggests, after reading a particular case study, students may held online discussions by taking over different perspectives with regard to the roles available in the case study. These online collaborative formats aiming at students' reflection, debate and interaction can effectively make the students go beyond being merely exposed to content and critically interact with it if the faculty members practice modelling reflective conversations, coaching, questioning and task structuring.

In order for the Internet to be used more than as a platform for the course content and as a communication medium for online-discussions, Kanuka [8] suggests that the following learning principles and strategies (see Table 2.) be applied to facilitate higher levels of learning [8].

Table 2. Principle Based Strategies for Learning

\begin{tabular}{|l|l|}
\hline Principles of Learning & Examples of Technologies \\
\hline Assume greater responsibility & $\begin{array}{l}\text { Online collaborative projects, } \\
\text { presentations, use of blogs or } \\
\text { wikis for reflective writing, e- } \\
\text { portfolios }\end{array}$ \\
\hline $\begin{array}{l}\text { Meaning making into } \\
\text { abstracted phenomena }\end{array}$ & $\begin{array}{l}\text { Scaffolded online discussion, } \\
\text { webinars, online debates }\end{array}$ \\
\hline Reconstruction of meanings & $\begin{array}{l}\text { Synchronous computer } \\
\text { mediated discussions, online } \\
\text { role playing, online } \\
\text { brainstorming sessions }\end{array}$ \\
\hline
\end{tabular}

2.1.1 Engagement with complex abstracted phenomena: Active and purposeful engagement can better occur if the following technologies are utilized:

- Simulations: Problems that are ambigious and don't present one right solution to the learner can best be presented via simulations.

- Microworlds: Collaborative learning strategies that are necessary for the intellectual participation between the learners and instructors can best be embedded within microworlds.

- Virtual worlds: The use of online worlds such as SecondLife count as alternative teaching methods for engaging learners in problem-solving. 
2.1.2 Multiplicity of perspectives: In order to present diverse perspectives about problems the following technologies can be used:

- Podcasts: Making use of several disciplines via podcasts is crucial for critical thinking.

- Blogs/wikis: Two or more occurrences that are contradictory can in-depth be discussed via blogs and wikis.

- Open educational resources: Information sets with diverse perspectives on an issue can be provided via various open educational resources provided by major universities such as MIT or Berkeley.

2.1.3 Relatedness: Phenonema that has relevance to learners must be involved, the following technologies can support this:

- Chats/forums/online discussions: Teachers as a credible authority in the field can create an intellectually stimulating environment by asking open-ended questions via threaded discussions.

- Podcasts: Phenomena that are related to an actual event can best be conveyed through podcasts.

- Concept maps: To nsure that meaningful understanding occurred concept maps about a particlat subject can be created.

2.1.4 Diverse ways of knowing: This principle can further be supported by the use of the following technologies:

- Wikis: Position, conclusion, passing of judgement on an issue after evaluating the alternatives and assessing the consequences can be practiced in wikis.

- Chats/forums/online discussions: Explaining, deciphering and resolving an ambiguous problem can be facilitated via use of threaded discussions.

Within the light of this information, in order to convey critical thinking skills, the instructors must focus on teaching the process of information discovery within the learner's own contextual meaning. This may be realised when the learners themselves select their own path of inquiry, get introduced to the necessary new technologies such as Web 2.0 based online collaboration tools when required and interact in the online setting in such a way that requires a high level cognitive involvement in order to self-construct their knowledge. To exemplify, student in a social science course could collaboratively author a paper similar to the process undertaken by professional researchers to publish their research in a peerreviewed form. Students can choose an existing topic or propose a new topic for addition to the site. Before their work is being peer-reviewed and published each group may be given a private wiki page for drafting their outline and taking notes. After the initial draft they can use the wiki as a collaborative writing space whereas the teacher can check their notes to ensure that they are on the right track. The peer-review group can post comments on the wiki page so that these can also be incorporated into the original work before the publication. In this way, the students may feel motivated to publish a high quality product and the teacher can assess their work and provide guidance throughout the whole publication process. By sharing ideas online and getting feedback, the social science classrooms can become a meeting place for the generation of new ideas.

Using wikis in social sciences will not only make the knowledge construction process much more transparent, but also provides the establishment of a learning community. Bransford, Brown and Cocking [2] state that direct cognitive and socio-collaborative support for the group members' efforts may be provided through a community of practice whereas the learners distribute their intellectual activity so that the burden of managing the whole process does not fall to any one individual.

As van Gelder [19] state a co-learning approach to hypertext expands critical thinking to involve the examination of various viewpoints and assumptions.By following paths throughout the hypertext web, students can keep track of their thinking processes reflectively and add new associative paths into the collaborative spaces by merely clicking the mouse. Similarly, it is asserted that by creating hypertext links students' learning experiences may become messy which is in fact indicative of the complicate process of meaningful learning [14]. Complex, multilinear and intertextual learning dispositions provide not only the opportunity for finding and making connections and reflecting upon the validity of these connections but also make the students discover that learning is in a constant state of change and growth rather than static [19]. Furthermore, with regard to online learning, the learning environments must possess an appropriate instructional design to support the students in developing their point of view and being critical. Yet, online education has often become an industrialized process of teaching and learning where students are not encouraged to apply knowledge in a variety of ways. A shift from the Fordist approach of learning that views learning as standardized and bureaucratic processes to a PostFordist approach where learning is seen as tailored products using decentralised approaches and learner-centered models may also provide the opportunity for online learning to improve critical thinking skills. 
Additionally, use of case-based reasoning, flowcharts and concept maps, minute papers, problem-based group learning all may be used to further promote critical thinking in online environments. So, case studies, role-playing, simulations, streamed video, chat rooms, bulletin boards, online references can facilitate an interactive online learning environment. These activities can foster group problem solving and hence encourage critical reasoning more than the traditional classroom instruction. Another way for fostering the critical thinking skills in online courses may be by use of concept maps of the understanding of the concepts addressed in the online discussions as Novak and Gowin [13] suggest. Based on Kolb's [10] learning type of concrete experience and active experimentation, concept maps support the learners in processing and generating information and self-assessing theirthinking processes. By looking at the concept map and thinking back to the online discussion the learners can see the relationships between the concepts they read and the online discussion.

\section{Conclusion}

Needless to say, each day we are getting exposed to a vast amount of information at an increasing rate. Similarly, social science students are expected to increase their knowledge base due to the information readily available. Yet, to build on what they already know requires critical thinking. The social science students must develop skills to not only examine logical relationships between statements but also construct arguments, respect different points of views and be flexible to change their way of thinking if reason leads them to do so. By actively conceptualizing, analyzing, synthesizing and evaluating information, an intellectual excellence can be achieved. The social sciences faculties can contribute to this intellectual growth by especially making their students engaged in online discussions and presentation tools.

It is the researcher's belief that by making students conveyors of their ideas via use of these interactive technologies and collaborative dialogue their ability to analyze, synthesize and evaluate solutions to real-life problems may be improved. Critical thinking happens in the presence of problem solving skills, creativity and dialogical interaction that lead to the challenging of assumptions and theory generation. So, by designing online courses from the bottom up that use the university's computer networking infrastructure which allows the opportunity for peer-to-peer dialogues as well as entail an online university speaker series social science departments may enhance the critical thinking skills of their learners.

\section{References}

[1] Bogdan, R. J., (2000) Minding minds. Cambridge MA: MIT Press.

[2] Bransford, J. D., Brown, A.L., Cocking, R.R., (Eds.). (2000) How People Learn: Brain, Mind, Experience, and School. Washington, D.C.: National Research Council.

[3] Cohen, M.S., Adelman, L., Bresnick, A., Marvin, F., Salas, E., Riedel, S. (2004). Dialogue as a medium (and message) for training critical thinking.http://www.cog-

tech.com/papers/Dialogue/Dialogue_Based_Traini ng_NDM6_May_2004.pdf (accessed August 20, 2008).

[4] Dewey, J., 1933. Experience and education. Macmillan, New York.

[5] Dumke, G., 1980.Chancellor's Executive Order 338. California State University, Chancellor's Office, Long Beach.

[6] Ennis, R. 2002.A super streamlined conception of critical thinking. http://faculty.ed8uiuc.edu/rhennis/SSConcCTApr3. html (accessed August, 21, 2008).

[7] Freire, P., 1994. Pedagogy of the oppressed. New York: The Continuum Publishing Company. (Original work published in 1970).

[8] Kanuka, H., 2002 "A Principled Approach to Facilitating Distance Education: The Internet, Higher Education and Higher Levels of Learning. Journal of Distance Education, Vol17, No: 2, 7086.

[9] Kolas, L., Staupe, A., "Implementing delivery methods by using pedagogical design patterns", Norwegian University of Science and Technology.

[10] Kolb, D. A., (1984). Experiental learning: Experience as the source of learning and development. Englewood Cliffs: Prentice Hall.

[11] Lampert, N., 2005.A comparison of the critical thinking dispositions of arts and non-arts undergraduates.PhD dissertation, College of William and Mary.

[12] Meyers, C., 1985. Teaching students to think critically. Jossey Bass, San Francisco. 
[13] Novak, J.D.,\&Gowin, D.B. (1984). Learning How to Learn. New York: Cambridge University Press.

[14] Pamela G. T., 2006. Critical Thinking in and through Interactive Computer Hypertext and Art Education.

http://www.innovateonline.info/index.php?view=ar ticle\&id=41\&action=article (accessed August 20, 2008).

[15] Paul, R., L. Elder, and T. Bartell. 1997. California teacher preparation for instruction in critical thinking: Research findings and policy recommendations. Sacramento, CA: California Commission on Teacher Credentialing.

[16] Perry, W. G., 1999. Forms of ethical and intellectual development in the college years: A scheme. San Francisco: Jossey-Bass.

[17] Savery, J. R. \& Duffy, T. M., 1995. Problem based learning: An instructional model and its constructivist framework. Educational Technology 33(1) 31-38.

[18] Sugar, W.A. \& Bonk C.J. 'Student Role Play in the World Forum'. Analyses of an Arctic Adventure Learning Apprenticeship," in Bonk, C.J. and King K.S (eds), Electronic Collaborators (Mahwah, N: Lawrence Erlbaum Associates, Publishers, 199), p.133.

[19] van Gelder, T., 2001. How to improve critical thinking using educational technology. Melbourne, Australia: University of Melbourne. http://www.philosophy.unimelb.edu.au/reason/pape rs/ASCILITE2001.pdf (accessed August 19, 2008). 